\title{
In vivo migration of dendritic cells labeled with synthetic superparamagnetic iron oxide
}

This article was published in the following Dove Press journal:

International Journal of Nanomedicine

27 October 20II

Number of times this article has been viewed

\section{Yongbin Mou' \\ Yayi Hou ${ }^{2}$ \\ Baoan Chen ${ }^{3}$ \\ Zichun $\mathrm{Hua}^{4}$ \\ Yu Zhang ${ }^{5}$ \\ Hao Xie ${ }^{2}$ \\ Guohua Xia ${ }^{3}$ \\ Zhiyong Wang' \\ Xiaofeng Huang' \\ Wei Han' \\ Yanhong $\mathrm{Ni}^{1}$ \\ Qingang $\mathrm{Hu}^{1,6}$}

'Central Laboratory of Stomatology, Stomatological Hospital Affiliated Medical School, Nanjing University, Nanjing, People's Republic of China; ${ }^{2}$ Immunology and Reproductive Biology Laboratory, Medical School, Nanjing University, Nanjing, People's Republic of China; ${ }^{3}$ Department of Hematology, Zhongda Hospital, Medical School, Southeast University, Nanjing, People's Republic of China; ${ }^{4}$ Jiangsu Key Laboratory of Molecular Medicine, Nanjing University, Nanjing, People's Republic of China; ${ }^{5}$ State Key Laboratory of Bioelectronics, Jiangsu Key Laboratory for Biomaterials and Devices, Southeast University, Nanjing, People's Republic of China; ' ${ }^{6}$ Leeds Dental Institute, Faculty of Medicine and Health, University of Leeds, Leeds, UK

Correspondence: Qingang Hu Central Laboratory of Stomatology, Stomatological Hospital Affiliated Medical School, Nanjing University, Nanjing 210008,

People's Republic of China

Tel +86258362 010I

Fax +86258362 020I

Email qghu@nju.edu.cn
Background: Successful treatment of cancer with dendritic cell tumor vaccine is highly dependent on how effectively the vaccine migrates into lymph nodes and activates T cells. In this study, a simple method was developed to trace migration of dendritic cells to lymph nodes.

Methods: Superparamagnetic iron oxide (SPIO) of $\gamma-\mathrm{Fe}_{2} \mathrm{O}_{3}$ nanoparticles were prepared to label dendritic cells generated from bone marrow of enhanced green fluorescent protein (EGFP) transgenic mice, to explore the fluorescence intensity of EGFP influenced by the SPIO, and to make images of labeled dendritic cells with the help of magnetic resonance imaging in vitro. The SPIO-EGFP-labeled dendritic cells were injected into the footpads of five mice. After 48 hours, magnetic resonance imaging, optical imaging, confocal imaging, and Prussian blue staining were used to confirm migration of the SPIO-EGFP-labeled dendritic cells into draining lymph nodes.

Results: The synthetic SPIO nanoparticles had a spherical shape and desirable superparamagnetism, and confocal imaging and Prussian blue staining showed perfect labeling efficiency as well. Furthermore, the dendritic cells dual-labeled by SPIO and EGFP could migrate into lymph nodes after footpad injection, and could be detected by both magnetic resonance imaging and optical imaging simultaneously, which was further confirmed by immunohistochemistry and Prussian blue staining. The percentage of dendritic cells migrated to the draining lymph nodes was about $4 \%$.

Conclusion: Synthetic SPIO nanoparticles are strong contrast agents with good biocompatibility, and EGFP transgenic dendritic cells can be labeled efficiently by SPIO, which are suitable for further study of the migratory behavior and biodistribution of dendritic cells in vivo.

Keywords: magnetic resonance imaging, optical imaging, dendritic cell, superparamagnetic iron oxide, cell tracking

\section{Introduction}

Superparamagnetic iron oxide (SPIO) nanoparticles are regarded as useful tools in numerous medical applications. ${ }^{1-3}$ Due to their small size, superparamagnetism, and inherent biocompatibility, they have been widely used in medical diagnosis, treatment, and even cell labeling and sorting. ${ }^{4-6}$ However, although they are promising materials for in vivo application, concern has been raised about their biological safety.

Dendritic cells are potent antigen-presenting cells that prominently express costimulatory molecules and are uniquely capable of inducing primary immune responses. ${ }^{7,8}$ Accumulating data on dendritic cells have shown them to induce strong antitumor immune responses in vitro and in vivo, and their efficacy has also been investigated. ${ }^{9-11}$ Essentially, dendritic cell immunotherapy is based on 
migration of these cells from the periphery to $\mathrm{T}$ cells via afferent lymphatics to generate potent immune responses. ${ }^{12}$ The dendritic cell migration process is complicated, involving a number of molecules, including chemokines, chemotactic receptors, adhesion molecules, and matrix metalloproteinases. ${ }^{13}$ Studies on dendritic cell trafficking have shown different migration patterns when using different routes of administration. Dendritic cell homing to the spleen and draining lymph nodes has been investigated after intravenous, intraperitoneal, subcutaneous, intradermal, and intranodal transfusion. ${ }^{10,14-18}$ Antigen-specific immune responses induced by dendritic cells via intranodal injection were similar to those after intradermal injection, ${ }^{10,14-16}$ and those induced by dendritic cells after intravenous infusion were similar to those after intradermal injection. ${ }^{10,18}$ It was noted that the ability of dendritic cells to migrate to lymph nodes was very limited after intravenous infusion, and that the footpad contains less fat tissue and a high density of lymph vessels. ${ }^{10,17}$ Thus, footpad injection was selected for investigation, which gave rise to similar migration efficiency as intradermal injection. ${ }^{18}$

Evaluation of dendritic cell migration efficiency requires a noninvasive imaging approach. At present, several noninvasive imaging methods for tracking dendritic cells have been reported, including planar gamma scintigraphy using gamma radiation-emitting radionuclides (such as ${ }^{11}$ inoxinate labeling), ${ }^{16}$ positron emission tomography with fluorine-18 labeling, ${ }^{19}$ magnetic resonance imaging with iron oxide magnetic nanoparticle labeling ${ }^{20-22}$ and optical imaging by luciferase or fluorescent dye labeling. . $32,24^{2}$ Studies have indicated that noninvasive, live, and highresolution $7 \mathrm{~T}$ or $11.7 \mathrm{~T}$ micro-magnetic resonance imaging enables detailed monitoring of magnetically labeled cells following infusion and provided a feasible method to evaluate the biological behavior of infused cell-based therapy. ${ }^{25,26}$ Optical imaging, which can be performed at high spatial and temporal resolution, has a high sensitivity for contrast agents, and is comparable with techniques used in nuclear medicine.

To overcome the limitations of the low sensitivity of magnetic resonance imaging compared with nuclear methods and the limited background anatomical information obtained from optical imaging, the two techniques were used jointly to observe dendritic cell migration into lymph nodes after footpad administration, which were labeled efficiently by transgenic enhanced green fluorescent protein (EGFP) and SPIO.

\section{Material and methods Experimental agents}

Ferric chloride $\left(\mathrm{FeCl}_{3} \cdot 6 \mathrm{H}_{2} \mathrm{O}\right)$, ferrous sulfate $\left(\mathrm{FeSO}_{4} \cdot 7 \mathrm{H}_{2} \mathrm{O}\right)$, and hydrochloric acid were purchased from Sinopharm Chemical Reagent Co Ltd (Shanghai, China). Tetramethylammonium hydroxide was obtained from Shanghai Lingfeng Chemical Reagent Co Ltd (Shanghai, China). RPMI medium 1640, penicillin and streptomycin were from Gibco Invitrogen (Grand Island, NY). Fetal bovine serum (Gibco, Life Technologies, Breda, the Netherlands), recombinant murine granulocyte-macrophage colony-stimulating factor, recombinant murine interleukin-4, tumor necrosis factor- $\alpha$ (TNF- $\alpha$ ), interleukin-1 $\beta$, interleukin-6 (Peprotech, Rocky Hills, NJ), prostaglandin $\mathrm{E}_{2}$ (Sigma-Aldrich, St Louis, MO) were also used, as well as a Prussian blue staining kit (Yuanye, Shanghai, China) and isoflurane (Abbott, Shanghai, China). Triton-X (Beyotime, China), and normal goat serum, rabbit anti-GFP probes, and goat antirabbit Alexa $488 \mathrm{~nm}$ were also used.

\section{Preparation of SPIO}

$\gamma-\mathrm{Fe}_{2} \mathrm{O}_{3}$ nanoparticles were prepared according to our previous work. ${ }^{14}$ Briefly, $200 \mathrm{~mL}$ aqueous tetramethylammonium hydroxide solution $1.5 \mathrm{M}$ was added to $500 \mathrm{~mL}$ of aqueous solution containing $\mathrm{FeCl}_{3} 0.1 \mathrm{M}$ and $\mathrm{FeSO}_{4} 0.05 \mathrm{M}$, with vigorous stirring at room temperature for 30 minutes. $\mathrm{The}_{3} \mathrm{O}_{4}$ nanoparticles obtained were washed by magnetic separation and redispersed in water at $\mathrm{pH} 3.0$ and a concentration of $3.0 \mathrm{mg} / \mathrm{mL}$, then oxidized into brown $\gamma-\mathrm{Fe}_{2} \mathrm{O}_{3}$ nanoparticles by aeration at $95^{\circ} \mathrm{C}$. The $\gamma-\mathrm{Fe}_{2} \mathrm{O}_{3}$ nanoparticles obtained were dialyzed using an aqueous solution of hydrochloric acid at $\mathrm{pH} 3.0$, with the final concentration adjusted to $25 \mathrm{mg} / \mathrm{mL}$ for cell label experiments.

The particle size and morphology of the $\gamma-\mathrm{Fe}_{2} \mathrm{O}_{3}$ nanoparticles were characterized using a transmission electronic microscope (JEM-2100; JEOL, Tokyo, Japan). The magnetic properties were measured using a vibrating sample magnetometer (Model 7407; Lake Shore, Westerville, OH). Photon correlation spectroscopy was used to determine the hydrodynamic size distribution using a Beckman Coulter N4 Plus submicron particle analyzer, and surface charge measurements were performed using a Beckman Coulter Delsa 440SX zeta potential analyzer (Indianapolis, IN).

\section{Mice}

Female C57BL/6 mice were purchased from the Animal Research Center of Yangzhou University, and EGFP-transgenic 
C57BL/6 mice were purchased from the Model Animal Research Center of Nanjing University, and housed in specified pathogen-free conditions at the Central Animal Facility, Nanjing University. In a typical experiment, bone marrow was isolated from the femur of 8-10-week-old mice weighing 20-22 g. All animal experiments were performed in accordance with protocols approved by the Animal Care and Use Committee of the Medical School, Nanjing University, China.

\section{Cell culture and labeling}

Dendritic cells were generated according to our previous work. ${ }^{15}$ Briefly, monocytes were isolated from the bone marrow of the mice. The marrow monocytes were flushed out from the femurs and tibias, cultured with RPMI 1640 supplemented with $10 \%$ fetal bovine serum, $50 \mathrm{mM}$ 2-mercaptoethanol, $100 \mathrm{mM}$ sodium pyruvate, $100 \mathrm{U} / \mathrm{mL}$ penicillin, $100 \mathrm{mg} / \mathrm{mL}$ streptomycin, $10 \mathrm{ng} / \mathrm{mL}$ recombinant granulocyte-macrophage colony-stimulating factor, and $1 \mathrm{ng} / \mathrm{mL}$ murine recombinant interleukin-4. On days 2 and 4 , $50 \%$ of the medium was removed and fresh medium was added. The released immature, nonadherent dendritic cells were collected on day 6 . The cells were stimulated with TNF- $\alpha 10 \mathrm{ng} / \mathrm{mL}$, interleukin- $1 \beta 10 \mathrm{ng} / \mathrm{mL}$, interleukin-6 $10 \mathrm{ng} / \mathrm{mL}$, and prostaglandin $\mathrm{E}_{2} 1 \mu \mathrm{g} / \mathrm{mL}$ for 48 hours. ${ }^{16,17}$ Mature dendritic cells were collected on day 8 and incubated with the SPIO $25 \mu \mathrm{g} / \mathrm{mL}$ for 12 hours at $37^{\circ} \mathrm{C}$ in $5 \% \mathrm{CO}_{2}$. Cellular phenotypes, viability, and function had been explored in our previously published work. ${ }^{16}$

\section{Prussian blue staining}

Mature EGFP transgenic dendritic cells were incubated with SPIO $25 \mu \mathrm{g} / \mathrm{mL}$ for 12 hours at $37^{\circ} \mathrm{C}$ in $5 \% \mathrm{CO}_{2}$. Cells were washed three times in phosphate-buffered solution and cytospins were prepared. Iron labeling efficiency was verified by Prussian blue staining and screened at high magnification (400×) using a light microscope (CKX41-A32PH; Olympus, Tokyo, Japan). Furthermore, laser confocal fluorescence microscope (Fluoview, Fv10i; Olympus) was performed to collect the EGFP fluorescence images.

\section{EGFP fluorescence intensity after SPIO labeling}

Mature EGFP transgenic dendritic cells were incubated with SPIO $25 \mu \mathrm{g} / \mathrm{mL}$ for 12 hours at $37^{\circ} \mathrm{C}$ in $5 \% \mathrm{CO}_{2}$. The cells were washed three times in phosphate-buffered solution. EGFP fluorescence intensity was studied by flow cytometry using Cell Quest software.

\section{Magnetic resonance imaging of SPIO-labeled dendritic cells in vitro}

$\mathrm{T}_{2}{ }^{*}$-weighted images of the SPIO were acquired with a Bruker Biospin 7.0 T scanner (Bruker BioSpin, Ettlingen, Germany) using a $38 \mathrm{~mm}$ rat head circular volume coil. For in vitro studies, $0.2 \mathrm{~mL}$ tubes with $1 \%$ agarose $50 \mu \mathrm{L}$, $1 \times 10^{4}, 1 \times 10^{5}$, and $1 \times 10^{6}$ SPIO-EGFP-labeled dendritic cells were placed into the tubes separately. These containers were positioned in the coil. The magnetic resonance sequence for evaluation of the cells was a fast low-angle shot gradient echo sequence. The parameters were set as follows: repetition time $471.1 \mathrm{msec}$; echo time $6.2 \mathrm{msec}$; flip angle 13 degrees; field of view $3.0 \times 3.0 \mathrm{~cm}^{2}$; matrix (MTX), $384 \times 384 \mathrm{~mm}^{2}$; slice thickness $0.28 \mathrm{~mm}$; and interslice distance $0.53 \mathrm{~mm}$.

\section{Magnetic resonance imaging in vivo}

For the in vivo studies, TNF- $\alpha(30 \mathrm{ng} / \mathrm{leg})^{20}$ was preinjected into the footpads of both hind legs $(n=5)$. After 24 hours, C57BL/6 mice were injected in the right footpads with $2 \times 10^{6}$ SPIO-EGFP-labeled dendritic cells in $40 \mu \mathrm{L}$ of phosphate-buffered solution, and in the left footpad with only $40 \mu \mathrm{L}$ phosphate-buffered solution as the control. After 48 hours, the mice were anesthetized by $4 \%$ isoflurane $/ \mathrm{O}_{2}$ $(\mathrm{v} / \mathrm{v})$ inhalation, placed on a warming pad, and maintained on $1 \%-2 \%$ isoflurane $/ \mathrm{O}_{2}(\mathrm{v} / \mathrm{v})$ throughout the experiments. Magnetic resonance imaging was performed and the phantom of mice popliteal lymph nodes was analyzed under the conditions of MSME-PD- $T_{2}$, echo time $65 \mathrm{msec}$, repetition time $3719.3 \mathrm{msec}$, field of view $2.70 \times 2.50 \mathrm{~cm}^{2}$, MTX $256 \times 256 \mathrm{~mm}^{2}$, interslice distance $0.7 \mathrm{~mm}$, slice thickness $0.5 \mathrm{~mm}$, and averages of 4 .

\section{Optical imaging ex vivo}

After magnetic resonance imaging, the optical imaging was performed. The bilateral popliteal lymph nodes were dissected, arranged on a black plate, and the optical images were obtained using a CRI optical imaging system (Maestro $^{\mathrm{TM}}, 2$ Maestro $^{\mathrm{TM}}$ Ex-RRO; Hopkinton, MA). The parameter was an excitation light source (484 $\mathrm{nm}$, diode laser) with a cold chargecoupled device camera (Nuance TX, Cambridge Research and Instrumentation, Woburn, MA) and an emission filter of $507 \mathrm{~nm}$. Ex vivo imaging data were analyzed using the Living Image software (v 2.50; Caliper Corporation, Newton, MA).

\section{Immunohistochemistry}

To analyze the in situ distribution of SPIO-EGFP-labeled dendritic cells, draining lymph nodes were dissected 
48 hours following administration of dendritic cells. They were embedded in optical cutting temperature (Sakura Finetek USA Inc, Torrance, CA). Cryosections $5 \mu \mathrm{m}$ thick were prepared, and fixed with 4\% paraformaldehyde for 30 minutes. The sections were blocked in $0.1 \%$ Triton-X and $10 \%$ normal goat serum for 1 hour, and incubated with molecular probes of rabbit anti-GFP overnight. After washing in phosphate-buffered solution three times, the sections were incubated with goat antirabbit Alexa $488 \mathrm{~nm}$ for 1 hour and investigated by confocal fluorescence microscope after washing by phosphate-buffered solution again. Other sections were verified by Prussian blue staining for iron detection.

\section{Percentage of EGFP-positive dendritic cells in lymph nodes}

For analyzing the percentage of EGPF-positive dendritic cells in the lymph nodes, $2 \times 10^{6}$ SPIO-EGFP-labeled dendritic cells in $40 \mu \mathrm{L}$ phosphate-buffered solution were injected in the right footpads of the mice preinjected by TNF- $\alpha$ (30 ng/leg). The popliteal and inguinal lymph nodes were dissected after 48 hours, pooled, disrupted mechanically, washed twice with phosphate-buffered solution, fixed in $2 \%$ paraformaldehyde, and the EGFP autofluorescence of all lymph nodes was analyzed by flow cytometry.

\section{Results}

\section{Characterization of SPIO}

Characterization of the synthetic SPIO nanoparticles was described according to our previous work. ${ }^{27}$ Briefly, $\gamma-\mathrm{Fe}_{2} \mathrm{O}_{3}$ nanoparticles were measured at an average diameter of around $8.7 \mathrm{~nm}$ under a transmission electron microscope, and were found to have formed nearly spherical shape. Vibrating sample magnetometer demonstrated that the $\gamma-\mathrm{Fe}_{2} \mathrm{O}_{3}$ nanoparticles obtained possessed superparamagnetic behavior, with saturation magnetization of $60.4 \mathrm{emu} / \mathrm{g}$. The average hydrodynamic size in water was $92 \mathrm{~nm}$ and the zeta potential of the $\gamma-\mathrm{Fe}_{2} \mathrm{O}_{3}$ nanoparticles had a positive surface charge of $20.9 \mathrm{mV}$.

\section{Efficiency of SPIO-EGFP dendritic cell labeling}

To evaluate the potential of SPIO particles in tracking dendritic cells by magnetic resonance imaging and optical imaging, the ability of EGFP-labeled dendritic cells to phagocytose SPIO particles was first examined. Prussian blue staining as well as confocal fluorescence microscopic analysis showed that the cells were almost all labeled by SPIO, and expressed EGFP fluorescence after being cocultured for
12 hours with $25 \mu \mathrm{g} / \mathrm{mL}$ SPIO for labeling dendritic cells (Figure 1). To evaluate whether the EGFP fluorescence of dendritic cells might be influenced by SPIO, a flow cytometry assay was undertaken. The results indicated that there was no significant difference in fluorescence intensity between the labeled and nonlabeled groups (Figure 2).

\section{Magnetic resonance imaging of SPIO-labeled dendritic cells in vitro}

To define the threshold of magnetic resonance imaging detection for dendritic cell labeling in vitro, titration experiments with different numbers of labeled cells were performed. The detectable signal intensities gradually decreased with increasing concentration from $1 \times 10^{4}$ cells to $1 \times 10^{6}$ cells (Figure 3).

\section{Magnetic resonance imaging in vivo and optical imaging ex vivo}

Mice were imaged by magnetic resonance imaging, and the popliteal lymph nodes were monitored for signs of dendritic cell migration from the injected site using the MSME sequence. Within the nodes, a decrease in signal intensity (darkening) indicated the presence of SPIO-labeled dendritic cells. The homing of dendritic cells into popliteal lymph nodes was noninvasively detected by magnetic resonance imaging. The darkened image from the popliteal lymph node of the right hind leg suggested that SPIO-labeled dendritic cells had successfully migrated from the injected site (footpad) into the draining lymph nodes (Figure 4A). To extend this study, EGFP imaging was performed ex vivo. The dissected popliteal lymph nodes were examined by optical imaging. The results confirmed migration of the SPIOEGFP-labeled dendritic cells in bright lymph nodes, which was in accordance with the magnetic resonance imaging (Figure 4B, C, and D).
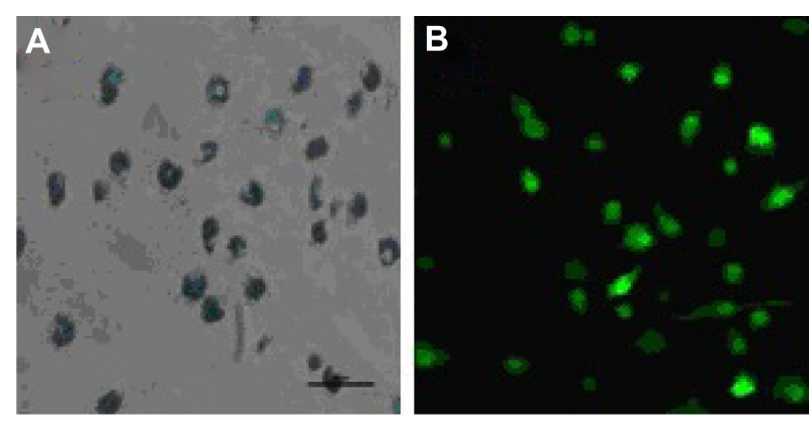

Figure I Morphology of dendritic cells labeled with $25 \mu \mathrm{g} / \mathrm{mL}$ superparamagnetic iron oxide particles after 12 hours incubation. (A) Labeled dendritic cells (Prussian blue staining, 400x) and (B) green fluorescence of enhanced green fluorescent protein transgenic dendritic cells $(400 \times)$. 

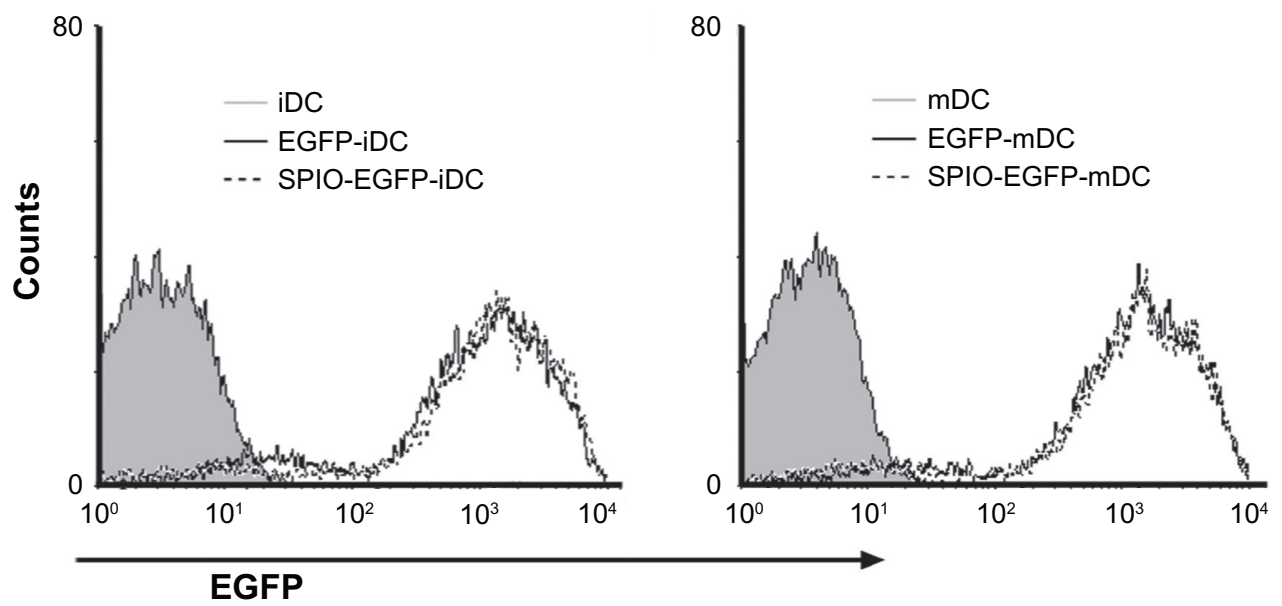

Figure 2 Fluorescence intensity of EGFP-transgenic dendritic cells labeled with $25 \mu \mathrm{g} / \mathrm{mL}$ SPIO particles after 12 hours incubation.

Abbreviations: SPIO, superparamagnetic iron oxide; EGFP, enhanced green fluorescent protein; iDC, immature dendritic cells; mDC, mature dendritic cells.

\section{SPIO-EGFP-labeled dendritic cells in draining lymph nodes}

To answer the question of whether dendritic cells migrate to lymph nodes after being injected into the footpad of the syngeneic mouse, the lymph nodes were dissected, sectioned, and subjected to anti-EGFP antibody staining for EGFP detection and to Prussian blue staining for iron detection. Clear EGFP fluorescence and blue staining localized in the cortical area of the popliteal lymph nodes confirmed the presence of EGFP and SPIO. By contrast, there was no fluorescence or blue staining detected on the control side and bilateral inguinal lymph nodes, which indicated that no dendritic cells migrated into nondraining and secondary draining lymph nodes (Figure 5B).

\section{Migrated dendritic cells in draining lymph nodes}

After confirmation of migration of SPIO-EGFP-labeled dendritic cells into the lymph nodes, the percentage of migrated dendritic cells was calculated. Single-cell suspensions of draining and non-draining lymph nodes were prepared and analyzed by flow cytometry. The mean percentages of EGFPpositive cells in the right popliteal and inguinal lymph nodes were $12.27 \%$ and $8.10 \%$, and in the left popliteal and inguinal

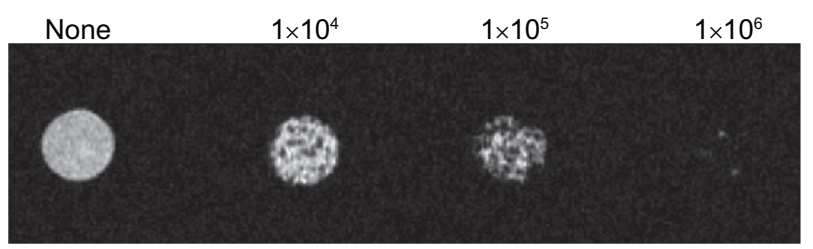

Figure 3 Signal intensity of superparamagnetic iron oxide-labeled dendritic cells ( $25 \mu \mathrm{g} / \mathrm{mL}, 12$ hours incubation) by magnetic resonance imaging in vitro assay. lymph nodes were $5.78 \%$ and $5.89 \%$. The difference between the right popliteal lymph nodes and inguinal lymph nodes was about 4\%, which means about 4\% EGFP-positive dendritic cells were found in draining popliteal lymph nodes, while the result of inguinal lymph nodes was negative (Figure 6).

\section{Discussion}

Dendritic cells are the major antigen-presenting cells in the initiation and development of the adaptive immune response against bacteria, viruses, allergens, and tumor antigens. However, many clinical trials designed to investigate the efficacy of dendritic cell vaccines for inducing immunity against tumors did not elicit effective antitumor immunity. ${ }^{28,29}$ One reason for the lack of therapeutic efficacy was the fact that most of the injected dendritic cell vaccines remained

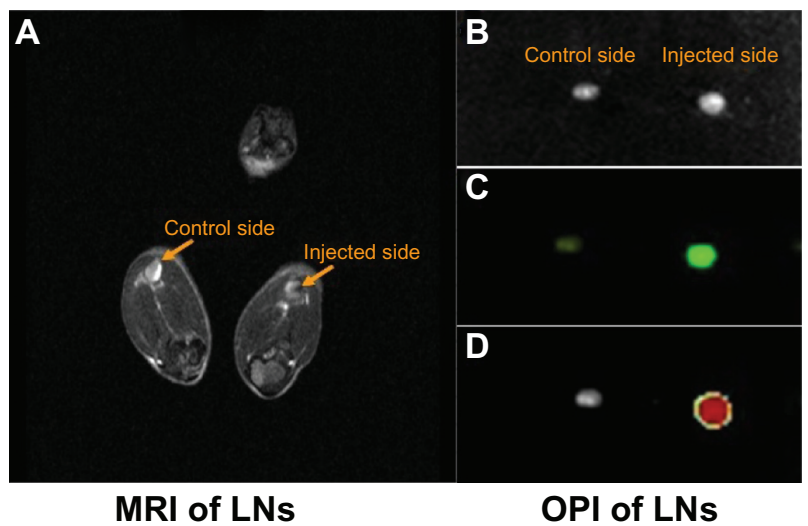

Figure 4 Superparamagnetic iron oxide-enhanced green fluorescent protein-labeled dendritic cells homing to the draining lymph nodes. (A) Labeled DCs homing to the popliteal lymph node by MRI assay in vivo, (B) dissected popliteal lymph node, (C) OPI of popliteal lymph node ex vivo, (D) OPI of popliteal lymph node analyzed using Living Image software.

Abbreviations: DCs, dendritic cells; MRI, magnetic resonance imaging; OPI, optical imaging; LN, lymph nodes. 

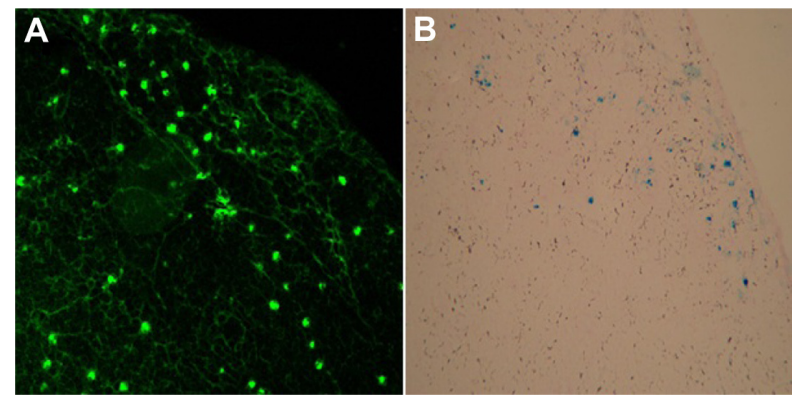

Figure 5 Morphology of superparamagnetic iron oxide-enhanced green fluorescent protein-labeled dendritic cells in draining lymph nodes after being stained with (A) immunohistochemistry and (B) Prussian blue staining (400x).

at the injection site and only a few migrated into draining lymphatic tissue. ${ }^{10,16}$ How to track and enhance dendritic cell migration in vivo and how to detect these cells by noninvasive techniques have become the most urgent questions. In this study, we used a combined approach of magnetic resonance imaging and optical imaging to explore migration of EGFPpositive dendritic cells generated from the bone marrow of EGFP-transgenic mice, using the technique of synthetic SPIO labeling.

SPIO, which is a biodegradable and feasible agent for magnetic resonance imaging of living cells both in vitro and in vivo, ${ }^{5,22}$ is an attractive contrast agent for monitoring cell migration. Due to the phagocytotic properties and negative cytomembrane potential of dendritic cells, SPIO nanoparticles could be easily delivered into dendritic cells, ${ }^{30}$ as indicated by Prussian blue staining. The treatments were nontoxic and did not interfere with the phenotypes and functions of dendritic cells after iron particle internalization. ${ }^{31,32}$
EGFP-positive dendritic cells derived from EGFP transgenic mice have the advantage of continuous expression of green fluorescence compared with other fluorescent dyes. Previous results have demonstrated that EGFP is not only a good tool for tracking dendritic cell migration, but also a marker of viability of dendritic cells, because dying dendritic cells rapidly lose their autofluorescence. ${ }^{18}$ There was strong fluorescence of EGFP in all cells on confocal fluorescence microscopy (Figure 1). To confirm that the cells migrating into tissues were indeed viable SPIO-EGFP-labeled dendritic cells, and not nonviable dendritic cells or phagocytes which had taken up the dead dendritic cells or released SPIO, the two combined techniques of magnetic resonance imaging and optical imaging were deployed using the SPIO and EGFP contrast agents.

Before application in vivo, the influence of SPIO labeling on the surface molecules, viability, and maturation of the dendritic cells were investigated in vitro. ${ }^{31}$ Briefly, nearly $100 \%$ of the dendritic cells were revealed to contain iron, there was little influence on cell apoptosis and expression of CD80, CD86, MHC-II, and CCR7 on the surface of mature dendritic cells had been little influenced by SPIO labeling. ${ }^{31}$ Based on these data, it could be concluded that the SPIO nanoparticles possessed good biocompatible characteristics and were suitable for use in investigation of the migratory behavior and biodistribution of dendritic cells in vivo. Another important aspect of dendritic cell migration was whether the SPIO could affect the fluorescence intensity of EGFP. The results of flow cytometry showed that the synthetic SPIO had no influence on the fluorescence signal from EGFP dendritic cells (Figure 2).
A

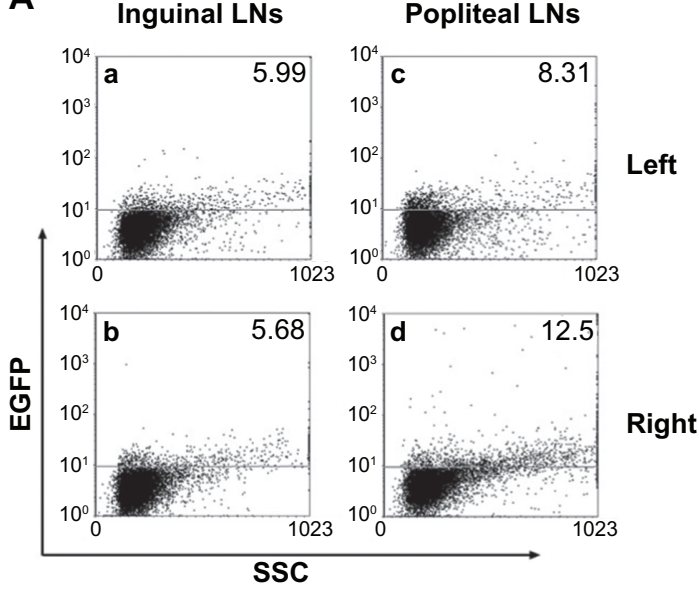

$\mathbf{B}$

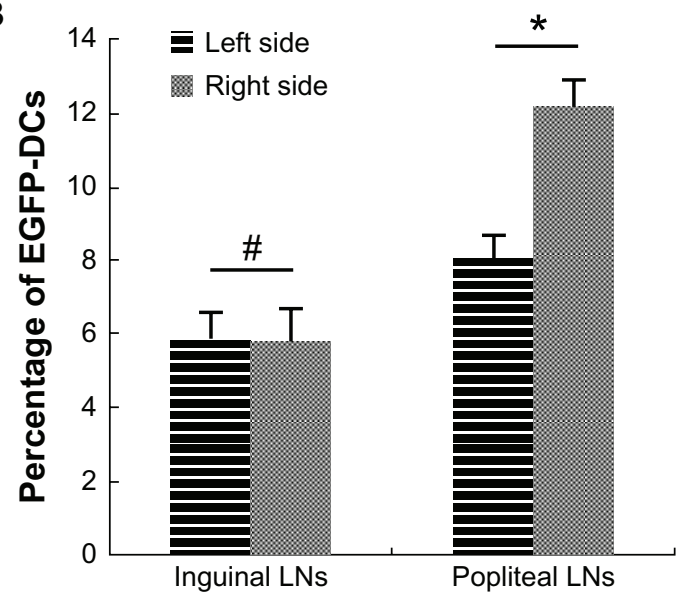

Figure 6 Analysis of EGFP fluorescence by flow cytometry. (A) EGFP fluorescence in both sides of inguinal and popliteal lymph nodes. (a) Left inguinal lymph node, (b) right inguinal lymph node, (c) left popliteal lymph node, and (d) right popliteal lymph node. (B) percentage of EGFP fluorescence on both sides of inguinal and popliteal lymph nodes).

Notes: ${ }^{\#} P=0.80>0.05 ; * P=0.0000287<0.05$

Abbreviations: EGFP, enhanced green fluorescent protein; LNs, lymph nodes; DCs, dendritic cells. 
Since the immune response based on dendritic cell vaccines against tumors is often shown to be weak or localized, how to track the migration of dendritic cells in vivo accurately has become a major concern. To overcome these deficiencies in this study, the two techniques of magnetic resonance imaging and optical imaging were combined to explore double-labeled dendritic cells from EGFP transgenic mice, in which EGFP was continuously expressed during differentiation of bone marrow monocytes. Meanwhile, the SPIO had little influence on dendritic cells, which served as excellent tools for tracking of dendritic cell migration in vivo.

Before the study of dendritic cell migration, the infusion method was still under investigation. Footpad injection was applied in this study and regarded as an intradermal approach because there is little hypodermis located there and it is feasible for footpad administration as well. Due to the weak migratory ability of dendritic cells in vivo, the footpads were pretreated with the inflammatory cytokine, TNF- $\alpha(30 \mathrm{ng} / \mathrm{leg})$, to increase the migratory ability of dendritic cells by upregulating expression of chemokines in the draining lymph nodes. ${ }^{20}$ As a result, the dendritic cells could easily migrate into the draining popliteal lymph nodes (Figure 4).

The disadvantage of common techniques, such as gamma scintigraphy, positron emission tomography, and single photon emission computed tomography, is their lack of spatial resolution, a prerequisite for precise anatomical localization of migrated dendritic cells in vivo. Due to the high spatial resolution and sensitivity of noninvasive imaging, magnetic resonance imaging and optical imaging have recently been used for tracking magnetic and fluorescent dye double-labeled cells in vivo. SPIO-EGFP-labeled dendritic cells were injected into the mouse footpads, and strong EGFP and SPIO signals could be detected in popliteal lymph nodes areas 48 hours later (Figure 4). The percentage of migrated dendritic cells into the lymph nodes was about $4 \%$ (Figure 6), which is similar to other reports, ${ }^{12,18}$ but less than the $9 \%$ reported by other researchers..$^{24}$ The differences may be due to the different calculation method (fluorescence imaging analysis) or the method used to count the migration time, such as observation after 72 hours following dendritic cell injection. Because dendritic cells are specialized antigen-presenting cells and larger than $\mathrm{T}$ cells, rosettes will be formed when $\mathrm{T}$ cells encounter dendritic cells. After intradermal injection, most dendritic cells remained at the injected site, died, and were cleared by macrophages, so only about $4 \%$ of dendritic cells reached the draining lymph nodes. Limited numbers of dendritic cells in the draining lymph nodes are still sufficient to induce antigen-specific immunologic responses. ${ }^{10}$
Noninvasive methods of magnetic resonance imaging and optical imaging using SPIO and EGFP labeling enabled us to image and analyze dendritic cell migration into draining lymph nodes in vivo. The immunohistochemical results demonstrated obvious diffuse distribution of blue iron within the lymph node after EGFP-SPIO-labeled dendritic cells were injected into the footpad. The confocal assay also confirmed that EGFP was present within the lymph node in the experimental side, but EGFP was not detected on the control side or secondary draining inguinal lymph node. These results are also in accordance with other studies. . $^{12,33,34}$

The data presented here demonstrated migration of SPIO-EGFP-labeled dendritic cells by magnetic resonance imaging and optical imaging, providing an excellent tool to track dendritic cells towards target organs or tissues in living organisms. It would be simple to study dendritic cell migration. Consequently, initial experiments for tracking of fluorescence dye and magnetosome-labeled dendritic cells to monitor their dynamic migration in vivo are currently being investigated.

\section{Acknowledgments}

The authors are grateful for grants from the National Natural Sciences Foundation of China (No 30870679, 81072213), the National Important Science Research Program of China (No 2011CB933503), the Research Project of the Jiangsu Department of Health (No H200944), and the Nanjing Medical Development Foundation (No ZKX10031).

\section{Disclosure}

The authors report no conflicts of interest in this work.

\section{References}

1. Singh R, Lillard JW Jr. Nanoparticle-based targeted drug delivery. Exp Mol Pathol. 2009;86:215-223.

2. Peng XH, Qian X, Mao H, et al. Targeted magnetic iron oxide nanoparticles for tumor imaging and therapy. Int J Nanomedicine. 2008;3: 311-321.

3. Comes Franchini M, Baldi G, Bonacchi D, et al. Bovine serum albumin-based magnetic nanocarrier for MRI diagnosis and hyperthermic therapy: a potential theranostic approach against cancer. Small. 2010;6: 366-370.

4. Long CM, van Laarhoven HW, Bulte JW, Levitsky HI. Magnetovaccination as a novel method to assess and quantify dendritic cell tumor antigen capture and delivery to lymph nodes. Cancer Res. 2009;69: 3180-3187.

5. Chen R, Yu H, Jia ZY, Yao QL, Teng GJ. Efficient nano iron particlelabeling and noninvasive MR imaging of mouse bone marrow-derived endothelial progenitor cells. Int J Nanomedicine. 2011;6:511-519.

6. Naqvi S, Samim M, Abdin M, et al. Concentration-dependent toxicity of iron oxide nanoparticles mediated by increased oxidative stress. Int J Nanomedicine. 2010;5:983-989.

7. Avigan D. Dendritic cells: development, function and potential use for cancer immunotherapy. Blood Rev. 1999;13:51-64. 
8. O'Neill DW, Adams S, Bhardwaj N. Manipulating dendritic cell biology for the active immunotherapy of cancer. Blood. 2004;104: 2235-2246.

9. Wierecky J, Muller MR, Wirths S, et al. Immunologic and clinical responses after vaccinations with peptide-pulsed dendritic cells in metastatic renal cancer patients. Cancer Res. 2006;66:5910-5918.

10. Verdijk P, Aarntzen EH, Lesterhuis WJ, et al. Limited amounts of dendritic cells migrate into the T-cell area of lymph nodes but have high immune activating potential in melanoma patients. Clin Cancer Res. 2009;15:2531-2540.

11. Cao Q, Jin Y, Jin M, et al. Therapeutic effect of MIP-1alpha-recruited dendritic cells on preestablished solid and metastatic tumors. Cancer Lett. 2010;295:17-26.

12. Martin-Fontecha A, Sebastiani S, Hopken UE, et al. Regulation of dendritic cell migration to the draining lymph node: impact on T lymphocyte traffic and priming. J Exp Med. 2003;198:615-621.

13. Adema GJ, de Vries IJ, Punt CJ, Figdor CG. Migration of dendritic cell based cancer vaccines: in vivo veritas? Curr Opin Immunol. 2005;17: 170-174.

14. Creusot RJ, Yaghoubi SS, Chang P, et al. Lymphoid-tissue-specific homing of bone-marrow-derived dendritic cells. Blood. 2009;113: 6638-6647.

15. Huck SP, Tang SC, Andrew KA, Yang J, Harper JL, Ronchese F. Activation and route of administration both determine the ability of bone marrow-derived dendritic cells to accumulate in secondary lymphoid organs and prime CD8+ T cells against tumors. Cancer Immunol Immunother. 2008;57:63-71.

16. De Vries IJ, Krooshoop DJ, Scharenborg NM, et al. Effective migration of antigen-pulsed dendritic cells to lymph nodes in melanoma patients is determined by their maturation state. Cancer Res. 2003;63:12-17.

17. Eggert AA, Schreurs MW, Boerman OC, et al. Biodistribution and vaccine efficiency of murine dendritic cells are dependent on the route of administration. Cancer Res. 1999;59:3340-3345.

18. Eggert AA, van der Voort R, Torensma R, et al. Analysis of dendritic cell trafficking using EGFP-transgenic mice. Immunol Lett. 2003;89: 17-24.

19. Olasz EB, Lang L, Seidel J, Green MV, Eckelman WC, Katz SI. Fluorine-18 labeled mouse bone marrow-derived dendritic cells can be detected in vivo by high resolution projection imaging. J Immunol Methods. 2002;260:137-148.

20. de Vries IJ, Lesterhuis WJ, Barentsz JO, et al. Magnetic resonance tracking of dendritic cells in melanoma patients for monitoring of cellular therapy. Nat Biotechnol. 2005;23:1407-1413.
21. Baumjohann D, Hess A, Budinsky L, Brune K, Schuler G, Lutz MB. In vivo magnetic resonance imaging of dendritic cell migration into the draining lymph nodes of mice. Eur J Immunol. 2006;36:2544-2555.

22. Verdijk P, Scheenen TW, Lesterhuis WJ, et al. Sensitivity of magnetic resonance imaging of dendritic cells for in vivo tracking of cellular cancer vaccines. Int J Cancer. 2007;120:978-984.

23. Schimmelpfennig $\mathrm{CH}$, Schulz S, Arber C, et al. Ex vivo expanded dendritic cells home to T-cell zones of lymphoid organs and survive in vivo after allogeneic bone marrow transplantation. Am J Pathol. 2005; 167:1321-1331.

24. Noh YW, Lim YT, Chung BH. Noninvasive imaging of dendritic cell migration into lymph nodes using near-infrared fluorescent semiconductor nanocrystals. FASEB J. 2008;22:3908-3918.

25. Ahrens ET, Feili-Hariri M, Xu H, Genove G, Morel PA. Receptormediated endocytosis of iron-oxide particles provides efficient labeling of dendritic cells for in vivo MR imaging. Magn Reson Med. 2003;49: 1006-1013.

26. Cao AH, Shi HJ, Zhang Y, Teng GJ. In vivo tracking of dual-labeled mesenchymal stem cells homing into the injured common carotid artery. Anat Rec (Hoboken). 2009;292:1677-1683.

27. Yong-kang Sun MM, Yu Zhang, Ning Gu. Synthesis of nanometer-size maghemite particles from magnetite. Colloids Surf A Physicochem Eng Asp. 2004;245:15-19.

28. Norian LA, Rodriguez PC, O'Mara LA, et al. Tumor-infiltrating regulatory dendritic cells inhibit CD8+ T cell function via L-arginine metabolism. Cancer Res. 2009;69:3086-3094.

29. Liu Q, Zhang C, Sun A, Zheng Y, Wang L, Cao X. Tumor-educated CD11b high Ialow regulatory dendritic cells suppress $\mathrm{T}$ cell response through arginase I. J Immunol. 2009;182:6207-6216.

30. Waeckerle-Men Y, Groettrup M. PLGA microspheres for improved antigen delivery to dendritic cells as cellular vaccines. Adv Drug Deliv Rev. 2005;57:475-482.

31. Mou Y, Chen B, Zhang Y, et al. Influence of synthetic superparamagnetic iron oxide on dendritic cells. Int J Nanomedicine. 2011;6: 1779-1786.

32. Tavare R, Sagoo P, Varama G, et al. Monitoring of in vivo function of superparamagnetic iron oxide labelled murine dendritic cells during anti-tumour vaccination. PLoS One. 2011;6:e19662.

33. Pham W, Xie J, Gore JC. Tracking the migration of dendritic cells by in vivo optical imaging. Neoplasia. 2007;9:1130-1137.

34. Christian NA, Benencia F, Milone MC, et al. In vivo dendritic cell tracking using fluorescence lifetime imaging and near-infrared-emissive polymersomes. Mol Imaging Biol. 2009;11:167-177.
International Journal of Nanomedicine

\section{Publish your work in this journal}

The International Journal of Nanomedicine is an international, peerreviewed journal focusing on the application of nanotechnology in diagnostics, therapeutics, and drug delivery systems throughout the biomedical field. This journal is indexed on PubMed Central, MedLine, CAS, SciSearch $\AA$, Current Contents $\AA /$ Clinical Medicine,

\section{Dovepress}

Journal Citation Reports/Science Edition, EMBase, Scopus and the Elsevier Bibliographic databases. The manuscript management system is completely online and includes a very quick and fair peer-review system, which is all easy to use. Visit http://www.dovepress.com/ testimonials.php to read real quotes from published authors. 